\title{
Implementing a School-Wide Ban on Single-Use Plastic Cutlery in a New Jersey Elementary School
}

\author{
A Case Study on the Scope and Limitations of the Role of School Leadership \\ in Incorporating Sustainable Development Practices into a School Agenda
}

Nidhi Thakur

\begin{abstract}
This case study focuses on the leadership an elementary school principal took in eliminating single-use plastic cutlery in his school cafeteria. He nurtured youth eco-activism, directed toward achieving a healthy and active school and based on practicing sustainable development. Although one might expect that climate activism would vary in proportion to the level of a school's resources, this case highlights that across all resource types, environment-friendly changes that question basic convenience are tough to introduce and implement and require persistence and planning. The case methodology involves a detailed timeline, constructed through interviews with the youth ambassadors, the parent-teacher organization, and the principal, of how the complete ban was ultimately accomplished by providing each student with free stainless-steel cutlery. The study aims to educate and inform education leaders how to navigate, with action and incentives, areas not directly related to academic goals. It is hoped that their engagement in sustainability issues can help challenge traditional static literacy and numeracy curriculums in favor of dynamic curriculums that, earlier in a student's life and ideally by the age of 15 , encompass sustainable lifestyles, as set out in UN's Sustainable Development Goals 4.7.4 and $4.7 \cdot 5$ on advancing the understanding of global citizenship and sustainability.
\end{abstract}

\section{Keywords}

school leadership - plastic bans - school climate

\section{Introduction}

In recent times, the role of school leaders in creating learning environments that ensure high academic achievement continues to be investigated with

(C) UNESCO IBE, 2021 | DOI: 10.1163/9789004471818_003

This is an open access chapter distributed under the terms of the CC BY 4 .o License. 
the explicit understanding that the role of the leadership is either only secondary or only complementary to that of the instructional teacher (Hitt \& Tucker, 2016). While the focus has typically been on resources and leadership for instructional excellence, the current case study investigates the role of a school leader in effecting tangible change in the school's orientation toward sustainable development.

This chapter takes a case study approach and discusses the initiatives taken by a principal in an elementary school in Millburn, New Jersey, US, to implement a ban on single-use plastic cutlery in the school. We develop a context for this ban and analyze its successful implementation with a focus on the role of the principal and of other constituencies that support him. Our goal was to understand what makes some school leaders undertake causes, such as sustainable development, that fall outside the conventional curriculum, and to make notes on the infrastructure, if any, that supports such a leadership model. This chapter aims to contribute to the discussion on the role and limitations of school leadership in enhancing the scope of school curriculums so that they include within their purview an understanding of sustainable development and climate change.

Single-use plastics, such as water bottles, cutlery, bowls, plates, and plastic wrap, form a sizeable, if not the largest, portion of the trash generated every day in school cafeterias. The school in Millburn faced such a situation. Whenever possible, schools can attack this problem through a tactic of "reuse and reduce". Such changes are not easy to implement, however, as they inconvenience users and may entail investment of both time and money.

During the summer break of 2019, a few students from the Millburn school system (which includes eight schools) participated in Columbia University's Eco Ambassador program. In this program the students self-selected, without consultation with their schools, various community-based environmental projects, including campaigns to reduce plastic consumption in the various shopping venues in town, and in schools. As the program gained visibility through word of mouth and social media, the Eco Ambassadors joined hands with the town-appointed environmental committee and with citizen activists 
to start lobbying for a town-wide ban on single-use plastic bags and straws. This, against a backdrop of a UN climate-action week in September 2019, culminated in a general movement toward reconsidering the use of single-use plastics in schools and in public places in the town.

Mr. F, the principal of this particular elementary school, had since May 2017 run a program called Change Agents, in which elementary students, picked annually by lottery, served on a committee that discussed topics and implemented strategies aimed at making students aware of ways they could bring about big and small changes. This program broadly targeted three areas:

- Environmental awareness: The students worked on being environmentally conscientious. They discussed recycling, beautification of the grounds and community, conservation, and ways to be healthy. The group was prepared to get its hands dirty doing service projects on school grounds, and perhaps even in the community.

- Ethics in action: The students discussed, and role-played scenarios commonly encountered at the elementary school level. They created, wrote, and performed skits for students. These incorporated a "power of one" theme and steps for conflict resolution.

- Random acts of kindness: The students were encouraged to make the world a better place through anonymous, random acts of kindness.

Even before the Change Agents program began, Mr. F had been part of a successful district-wide initiative discouraging the use of prepackaged bottled water. For that project, a local educational non-profit and the various parent-teacher organizations (PTOs) had come together to install water-bottle filling stations in schools throughout the district. In the context of that issue, Mr. F had gone a step beyond other schools and worked with his PTO to end completely the practice of offering bottled water with school lunches. That move had not only lowered the school's consumption of water bottles by 100,00o but had also reduced the cost of school lunches.

In October 2019, during a Change Agents meeting in which Mr. F reviewed the water bottle successes, the group discussed and debated and decided to address the issue of plastic utensils. Charged with a sense of purpose, the students researched the problem and wrote speeches to deliver to their peers at lunchtime. They made and hung posters around the school. They also agreed that it would be important to discuss the issue with families at home at mealtimes. The critical element was that the students were being energized to be agents and advocates of change by living this mission in school and at home. Mr. F personally committed to help them, and he provided a specific list of ways in which he would do so. 
This campaign, begun in October 2019, lasted two months until the end of the year, during which time the Change Agents students continued to speak with their peers about the issue as and when they could. When the school reopened in January after the winter break, Mr. F titled his carefully-crafted "welcome back" e-mail "A New Year's Initiative". In it, he called stakeholders' attention to the issue of single-use cutlery, laid down tangible steps for implementing a ban on it, and put out a manageable timeline for eliminating its use altogether by the end of February. The e-mail (which appears in the Appendix) first established a background by describing how the water-bottle filling stations had successfully eliminated the use of one kind of plastic. It also laid out the fail-safe measure for the current project, namely ensuring that no student would ever be "admonished" for not bringing reusable cutlery from home. Instead, Mr. F put his own money into the pilot project and bought two cartons of durable compostable cutlery for anyone without reusable cutlery from home.

The sincerity of the e-mail inspired a chain of events. The PTO soon volunteered to fund, as a gift to each student, a set of stainless-steel cutlery in a washable zippered bag especially designed for the purpose. The idea was to facilitate each student's carrying their own cutlery from home to school and back. The students could purchase additional zippered bags from the Рто, thus providing an extra fund-raising opportunity for the Рто. As the Рто board members state, their "generosity" was intended primarily to support the intentions of Mr. F.

One can imagine that expecting a whole community to give up a convenience it is used to would come with its own set of reservations. Mr. F stepped up to volunteer his own personal time for whatever he could do to overcome them. He wanted the teachers, too, to give up plastic cutlery in the teachers' lounge and at school fairs. So he proposed a way around teachers complaining about lack of time to wash stainless steel cutlery. He offered to have teachers dump their used cutlery in a bin, which he would himself pick up and deposit in the dishwasher each day. Gradually, teachers started washing their own cutlery at school, or taking it home to wash.

Mr. F's leadership style is "leading by doing", which is a big component of transformational leadership. To the extent that Mr. F first adopts a practice himself and then facilitates opportunities for students, teachers, and parents to collaborate on issues that are more than curriculum oriented, his goal appears to be that of creating not just a program but a culture of collective goals and greater 
good (Bass \& Avioli, 1993; Leithwood, 1994). In addition, he establishes influence by modeling practices that convey a sense of vision, mission, ethics, and aspiration (Fu, Tsui, Lui, \& Li, 2010; Marks \& Printy, 2003).

In this context, one can call Mr. F's approach to sustainable development a practitioner's approach. Besides having personally presided over the Change Agent meetings, he has demonstrated a practitioner's approach to health and exercise initiatives. Trained in the martial arts himself, he runs two sessions of free karate class every week as an after-school activity. Also, every semester he runs early morning exercise clubs for students before school. These activities are markedly absent from other elementary schools in the district. One can infer that Mr. F's style and investment of his personal time and energy into activities that go beyond an effort to simply boost numeracy, literacy, and test scores do lend legitimacy to a sense of his vision on the part of the relevant constituencies (teachers, parents, and students), who then support his vision with enthusiasm and funds.

It should be noted that the school in this study has a PTO whose annual budget often exceeds US $\$ 100,000$, whereas the typical pто in the United States has a budget of no greater than $\$ 15,000$. It is logical to ask whether a single-use cutlery ban propped up by the distribution of free stainless-steel utensils would be possible in a school with fewer resources, and with perhaps more problems, such as poor academic achievement or issues with student behavior. Mr. F believes that regardless of the resources on hand, he would be able, if needed, to mobilize resources, through grants or fund-raisers, for actions aligned with the goal of healthy habits. While his idea may or may not be as feasible in a different school, we can continue to give credit to the role of the principal here, by looking at the fact that in other schools in the district, in which the Рто funding and much of the body of students and of teachers resemble those in this school, neither a plastic-cutlery ban, nor early morning exercise clubs have been initiated. Thus, it appears that there is a role for individual initiative in the leadership positions.

Having said that, one can also recognize a limit to the degree to which school leadership can be tapped to bring sustainable development into fundamental curriculums. Mr. F is fully aware of the time challenges that teachers face in the school schedule, and he has thus never actively sought to incorporate sustainable development issues like climate science or global warming into the curriculums formally. One can claim that school curriculums are like the US Constitution and need long-drawn-out and extremely well-articulated reasons for change or "amendment". Perhaps what is needed is something like the New Jersey governor's March 9, 2020 announcement of state efforts to incorporate climate change into $\mathrm{K}-12$ curriculums. Such a policy might push individual school leaders to then actively seek the support of teachers toward shaping 
such curriculums. However, the actual impact of such policy announcements on school curriculums, albeit a ripe topic for another study, is beyond the scope of the current one.

We can conclude that Mr. F's approach is not to create additional work for his teachers or students, but instead to convert the community to a belief system in which sustainability is a natural choice and thus not a chore. He does so through his individual actions, cognizant that his actions have the advantage of a visibility that others' actions may not. Of all the moving parts - teachers, parents, other administrators, students - the young, impressionable students may most likely become lifelong practitioners of sustainable development, once these actions become a habit from early on.

We understand that the current study would be enriched by an understanding of why other schools in the district did not initiate the same cutlery ban. However, since the schools have been closed for remote study because of Covid-19, whose timing coincided with the ban in this school, we have no data on why and how other schools intended to follow with similar bans, if at all.

Similarly, we want to emphasize that while the current study highlights the active role of a school leader in undertaking outside-the-box activities that can contribute to the general good of a community and also orient students toward sustainable development, this role has limitations. The most glaring of these is that curriculum-setting remains a prerogative not of school leadership but of instructional staff. Nevertheless, an engaged school leadership can contribute to a school climate that can in turn foster such school and community interactions as to not only improve school academic outcomes, but also make other positive changes possible. One tenet of a good school climate, as defined by the National School Climate Center, is the fostering of youth engagement in caring for the physical environment. As we saw in our current study, the principal's well-meaning individual initiative on an environmental issue not directly linked to the curriculum can receive full-scale reinforcement by the Pто, thus enabling the adoption of exemplary sustainable development practices across the board.

Meanwhile, the students who had participated in the Eco Ambassador project in the summer of 2019 felt validated when at least one of eight schools implemented this ban, in addition to the town's passing its ordinance banning single-use plastic bags, straws, and Styrofoam utensils by all vendors.

\section{5} Conclusion

While academic proficiencies remain salient markers for assessing the validity of a school, it is time to reassess the role of the school in creating opportunities 
for students to examine their world from a sustainability perspective. In particular, given the average daily time that the impressionable young minds spend at school, it is only fair to expect that schools exemplify and amplify behaviors that better prepare students not just for changing economic and technological forces, but also for changing ecological environments. In particular, as SDG 4.7.5 puts it, every effort must be undertaken to advance the understanding of global citizenship and sustainability, ideally by the age of 15 . Surely, the goal is to inculcate sustainability as a habit as students advance through the school system into adulthood.

Our case-study demonstrates the significance and limitations of school leadership in a program directed toward inclusion of sustainability in the school agenda. The principal's ability to invest personal energy into the desired change can mobilize resources from a range of supporting infrastructure. At the same time, fundamental changes to school curriculums continue to be an exercise outside the capacity of any school leader to affect. What an effective leadership can help create is an environment for sustainable development practices to be incorporated into everyday school life. The hope is that as sustainable practices become more commonplace, a push could be generated from within the system by the students and parents themselves, demanding explicit incorporation of an inquiry into the unsustainable economic worlds that our curriculums currently prepare students for.

\section{References}

Bass, B. M., \& Avolio, B. J. (1993). Transformational leadership and organisational culture. Public Administration Quarterly, 17, 112-121.

Fu, P. P., Tsui, A. S., Lui, J., \& Li, L. (2010). Pursuit of whose happiness? Executive leaders' transformational behaviors and personal values. Administrative Science Quarterly, 55, 222-254.

Hitt, D. H., \& Tucker, P. D. (2016). Systematic review of key leadership practices found to influence student achievement: A unified framework. Review of Educational Research, 86(2), 531-569.

Leithwood, K. (1994). Leadership for school restructuring. Educational Administration Quarterly, 30, 498-518.

Marks, H. M., \& Printy, S. M. (2003). Principal leadership and school performance: An integration of transformational and instructional leadership. Educational Administration Quarterly, 39, 370-397. 


\section{Appendix: E-mail Sent by Mr. F as a Welcome-Back Message to Students in January 2020, after the Winter Break of 2019}

\section{Dear Parents,}

Happy New Year and welcome back!

Several years ago, students received a small 8-ounce plastic water bottle whenever they purchased a lunch. Additionally, children brought in their own plastic water bottles. In a school of 500 students, this turned out to be hundreds, or even thousands, of water bottles each week. Identifying this problem, with the generosity of the parent community and the support of the PTO, we installed water fountains that filter water, have a filling station for personal water bottles, and keep track of how much plastic we keep out of the environment.

We discontinued the sale of plastic water bottles at lunch and encouraged parents and students to use their own personal reusable, metal water bottles. To date, we've saved 47,000 16-ounce water bottles from the environment. That equates to almost 100,000 of the small water bottles that used to be served. A small shift in our belief and behavior has made a huge difference!

Eliminating the use of plastic utensils has been identified as our next initiative. As of February 24, when we return from the winter break, Hartshorn School will no longer use or offer plastic utensils.

Please send your child in with a reusable metal or wooden utensil that he or she will bring back home (no butter knives, please). A small container or closable cloth can be used to store and transport your child's spoon/ fork.

If you forget to pack a utensil for your child, he or she will be given an ecofriendly, compostable utensil to use, take home, keep, and reuse. At this time, you do not have to return it! https://compostables.org

A few children still bring in plastic water bottles, and there will be some who may continue to use plastic utensils. No students will ever be admonished for doing so. We are encouraging families to join the school on this journey.

Will all use of plastic water bottles and utensils be eliminated at Hartshorn? Most likely not. However, the idea is to try and do something that makes a positive change. As Maya Angelou has said, "Do the best you can until you know better. Then when you know better, do better".

You may also see and hear about our Change Agents moving forward with this initiative. I hope you join us in making this important difference! Thank you!

Sincerely,

Mr. F 